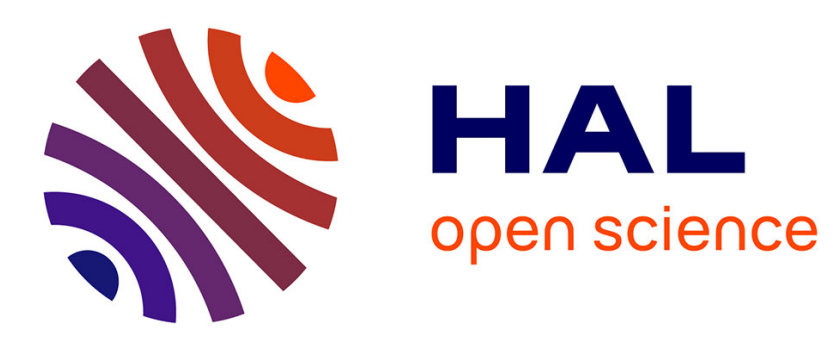

\title{
Bio-informed emerging technologies and their relation to the sustainability aims of biomimicry
}

Bernadette Bensaude-Vincent

\section{To cite this version:}

Bernadette Bensaude-Vincent. Bio-informed emerging technologies and their relation to the sustainability aims of biomimicry. Environmental Values, 2019, 28, pp.551-571. hal-02573574

\section{HAL Id: hal-02573574 \\ https://hal.science/hal-02573574}

Submitted on 14 May 2020

HAL is a multi-disciplinary open access archive for the deposit and dissemination of scientific research documents, whether they are published or not. The documents may come from teaching and research institutions in France or abroad, or from public or private research centers.
L'archive ouverte pluridisciplinaire HAL, est destinée au dépôt et à la diffusion de documents scientifiques de niveau recherche, publiés ou non, émanant des établissements d'enseignement et de recherche français ou étrangers, des laboratoires publics ou privés. 


\title{
Bio-informed emerging technologies
}

\section{and their relation to the sustainability aims of biomimicry}

Envrionmental Values, 28 (2019) : 551-571.

\author{
Bernadette Bensaude-Vincent \\ Emeritus Professor of Philosophy of technology \\ Université Paris 1 Panthéon-Sorbonne \\ 17 Rue de la Sorbonne \\ 75231 Paris 05 FRANCE \\ bvincent@u-paris1.fr
}

\begin{abstract}
Synthetic biology, materials chemistry, and soft robotics are fast becoming leading disciplines within the field of practices, which look to nature for inspiration and opportunities. In this article, I discuss how these molecular-scale practices fit within the existing trends of bio-informed design defined at the macro-level, i.e. bionics, biomimetics and more specifically biomimicry.

Based on the metaphysical views underlying bio-informed design practices, I argue that none of them currently fit the biomimicry model, as they are not consistently concerned with environmental sustainability. While biomimetic chemistry loosely belongs to the field of biomimetics, and soft robotics to the field of bionics, both practices have a profound impact on their respective fields, as they question the places of nature and engineers.
\end{abstract}

Keywords: bionics, biomimetics, biomimicry, chemistry, cybernetics, ecology, materials science, sustainability, synthetic biology. 
Twenty years ago, Janine Benyus spread the gospel of a 'Biomimicry revolution' in a popular book Biomimicry, Innovation inspired by Nature (1997). As the audience of this work expanded, biomimicry became the flagship of an alternative approach to technology and the promise of reconciliation of human technology and the planet. More recently, Idriss Aberkane, a French advocate of biomimicry, presented it as a "second Renaissance" opening up a sustainable industrial future in the context of the knowledge-based-bio-economy promoted by the European Commission (Aberkane 2015). ${ }^{1}$ Such claims are based on the conviction that biomimicry is the expression of a radical change in the relations between technology and nature.

However, Benyus's ideal of biomimicry, which equates learning from nature to environmental friendliness, is only one trend in a variety of other bio-informed design strategies. Indeed, the term "bio-informed technology" was defined in 2014 as part of a comparative analysis between bionics, biomimetics, biomimicry and bio-inspiration (Iouguina et al. 2014), as "the informed interpretation of biological research in order to address human challenges for the purpose of innovation that may or may not result in sustainable solutions" (Iouguina et al. 2014: 203).

Likewise, the concept of biomimetics defined by ISO as "knowledge gained from the analysis of biological systems to find solutions to problems, create new inventions and innovations, and transfer this knowledge to technical systems" (ISO 18458: 2015) does not include environmental references.

\footnotetext{
${ }^{1}$ According to the European Commission, the Knowledge-based-bio-economy (KBBE) is the sustainable, eco-efficient transformation of renewable biological resources into health, food, energy and other industrial products (Framework Programme 7, Theme 2: Food, Agriculture, Fisheries and Biotechnology (FAFB), 2007 Work Programme; DG Research, Commission of the European Communities: Brussels, Belgium, 2006.)
} 
While Iouguina et al. based their comparative analysis on a survey of practitioners in industrial design, engineering, architecture and economics, this paper compares emerging molecular scale design practices in three different research fields - synthetic biology, materials science \& engineering, and soft robotics.

Such practices were notably developed with the idea of providing novel solutions to problems caused by conventional technologies. I will not focus on this claim here, but on their philosophical implications with a view to comparing them to the metaphysical agenda of other bio-informed strategies, in particular biomimicry². As Vincent Blok and Bart Gremmen put it: "According to the proponents of biomimicry, it introduces a new and ecosystem friendly approach to nature, which is no longer characterized by the domination and exploitation of nature, but by learning and exploration" (Blok, Gremmen 2016: 204).

In contrast, bio-informed design in synthetic biology clearly shows that learning from nature does not necessarily rhyme with sustainability and environmental friendliness. Biomimetic materials research shows that, engineering concerns prevail over the integration of technology into natural cycles and processes. And whilst soft robotics, the heir of bionics, explores pathways of design, which disrupt the conventional rules of responsible engineering, they do not especially lead to more sustainable technology. In summary, none of the emerging molecular scale design practices presented here show specific sustainability or environmental concerns, which may create tensions in the politics of bioeconomy.

\section{A jungle of terms and movements}

\footnotetext{
${ }^{2}$ The assumption underlying this analysis is that scientific and technological practices are driven by a metaphysical framework, a set of tacit and taken for granted presuppositions about nature, life, and about the role of the mind and technology. Although they are not empirically testable, these assumptions are conducive of research orientations.
} 
Beyond bionics, biomimetics and biomimicry, a wide variety of technological design movements bearing fancy names such as biophilic, cradle-to-cradle or salutogenic design also claim to promote bio-informed strategies.

The term 'bionics', first used in 1958 by Jack Steele, an engineer of the US Air Force, was defined as "the science of systems whose function is based on living systems, or which have the characteristics of living systems, or which resemble these" (quoted in Vogel, 1998: 250). Its main objective was to design life-like machines with functions such as selforganization, self-replication, and self-repair, as part of the early cybernetics. Innovation is the main goal of bionics.

The term "biomimetics" was first coined during a Congress of Biophysics in 1969, by Otto Herbert Schmitt, a biophysicist who had developed a physical device mimicking the electrical activity of nerves as part of his PhD. Its main objectives are to design multifunctional and high-performance materials.

Biomimicry emerged out of ecological concerns to reconnect design with nature, with the main objectives to develop more sustainable technology rather than innovation. Increasing sustainability in technology was the driving force behind Benyus's unabated and enthusiastic advocacy of biomimicry. Thus, unlike bionics and biomimetics, biomimicry is mainly concerned with the invention and implementation of bio-inspired technological practices for environmental purposes. Benyus's book and consultancy spread the word of 'biomimicry', which became a success in the 2000s, leading to the creation of a Biomimicry Institute.

According to Iouguina et al., biomimicry follows a number of biological principles, sometimes at the cost of real-world applicability. In their view, biomimetics and bioinspiration are "the least concrete [strategies] in their broad context and objective" (Iouguina et al. 2014: 202). Whilst their attempt to clarify the terminology of bio-informed approaches to design stresses the differences between bionics, biomimetics and biomimicry, the 
landscape of bio-informed movements remains far more complex than suggested by Iouguina et al.

Firstly, the bionics movement, which promoted the ideal of self-organizing bionic machines was not devoid of environmental considerations. In an effort to promote ecological principles in agriculture, the New Alchemy Institute created in 1969 by John Todd, Nancy Jack-Todd and William McLarney recommended regional self-organized and self-sustaining productions against the mainstream productivist model of industrial agriculture. ${ }^{3}$ Likewise, the early US-born bionics movement was boosted by German zoologist Werner Nachtigall in the 1970s. Nachtigall redefined bionics as "learning from nature as an inspiration for independent technical design" and formulated a series of principles of bionic design, which included considerations such as energy saving and recycling (Wahl 2006: 292).

Secondly, Iouguina et al. failed to adequately characterize biomimetics. While they rightly place the origin of biomimetics in biophysics, the assertion that "unlike the general principles of biomimicry and bionics, the principles of biomimetics are based on nature's mechanical capabilities and rooted in specific examples from nature" is somewhat incomplete (Iouguina 2014: 198). The tradition initiated by Otto Schmitt with his work on electrical impulses in neural networks is more inspired by computer sciences than nature. In fact, Schmitt himself declared that most of his work was about algorithm and computer networks.

Since 1935, my scientific and technical efforts have revolved about the conviction that a new major discipline of biomedical science and technology will arise through careful examination and reformulation of biological principles in algorithmic computer-manipulable form, generating new mathematical figures of thought as needed, and seeking technological and social analogies based on these biomimetic principles.'(quoted in Geselowitz 1998:740).

\footnotetext{
${ }^{3}$ The tradition of agro-ecology initiated in the USA by Wes Jackson in contrast to productivist agriculture seems to have been a source of inspiration for Benuys's notion of biomimicry (Dicks 2017).
} 
In addition, Iouguina et al. ignore the case of biomimetics at the crossroad between chemistry and materials science, which became a research field of its own in 1985, with the publication of the first yearbook Biomimetic and Bioorganic Chemistry. Here, chemists and materials scientists working on specific applications in aerospace or biomedicine acknowledged that natural materials such as coccoliths, abalone, spider silk, gecko's feet, or lotus leaves were a source of inspiration to design high-performance, multi-functional materials. This led to the set-up of collaborations between marine biologists and material chemists to screen libraries of natural seashells, and design biomimetic synthetic equivalents. A new research field focusing on molecular-scale composite materials inspired by biominerals was born, preceding the advent of nanotechnology.

This back-to-nature movement in a chemistry culture previously known more for its praise of synthetics and cult of the artificial (Bensaude-Vincent 2007) was also prompted by the emergence of supramolecular chemistry, a field concerned with the self-assembly of molecules into chemical systems commonly found in biological architectures. Here, composite materials for aerospace or military applications were designed with the endproducts' functional demands in mind, as opposed to conventional materials previously developed with standard specifications and universal applications.

Thirdly, whilst the various trends within the biomimicry movement all share the same overarching commitment to ecological principles, they do not share the same worldview. Benyus, famously articulated her plea for biomimicry around three functions ascribed to nature: "Nature as a model" advocates imitating nature to solve technological problems. Interestingly, this assertion alone is also the minimum program of biomimetics. "Nature as a mentor" prescribes learning from nature and following her ways, rather than considering it as a mine of resources. "Nature as a measure" goes as far as assessing the relevance and validity of human innovations against natural systems. Indeed, Benuys's view of nature as the 
supreme judge of all human actions was so strongly normative that her philosophical framework became a metaphysical program.

Table 1: Comparing three major trends in bio-informed design

\begin{tabular}{|l|l|l|l|}
\hline Historical origin & Bionics & Biomimetics & Biomimicry \\
\hline Main goal & $\begin{array}{l}\text { Biophysics } \\
\text { Chemistry } \\
\text { like machines }\end{array}$ & $\begin{array}{l}\text { Ecological culture } \\
\text { Agriculture }\end{array}$ \\
\hline performance materials & $\begin{array}{l}\text { Developing sustainable } \\
\text { technology integrated into } \\
\text { nature }\end{array}$ \\
\hline $\begin{array}{l}\text { Metaphysical } \\
\text { assumptions }\end{array}$ & $\begin{array}{l}\text { Complexity } \\
\text { Life as computational } \\
\text { machine }\end{array}$ & $\begin{array}{l}\text { Focus on properties \& } \\
\text { performances of individual } \\
\text { materials }\end{array}$ & Holistic approach \\
\hline
\end{tabular}

\section{The metaphysical framework of biomimicry}

It is worth however to further explore the various versions of the biomimicry agenda in order to characterize its relations with the current practices of bio-informed design at the molecular scale. One major point is the claim that biomimicry brings about a revolution. Benyus for instance raised the question: "What will make the Biomimicry Revolution any different from the Industrial Revolution? Who's to say we won't simply steal nature's thunder and use it on the ongoing campaign against life?" (1997:8).

For Aberkane, the Biomimicry Revolution is different from the first Industrial Revolution because nature is treated as a source of knowledge, whereas in the first Industrial Revolution it was essentially a set of indefinite resources to be consumed. Nature is a library full of books. We should read them to learn from them instead of burning the archives of life, i.e. fossil resources. This metaphor connecting the "second Renaissance" (Aberkane 2015) 
with the old Book of Nature trope points to a stark contrast of anthropological attitudes. While the first Industrial Revolution initiated an economy of resources where consumption was the main objective, biomimicry supports a knowledge-based bio-economy, where learning becomes a priority. However, the medieval metaphor of the Book of Nature was embedded in a specific metaphysics: Nature and the Bible were the two books of God's revelation. Nature had a divine origin. It was a coherent whole created by an intelligent designer. This theological context provided the background for Galileo's oft-quoted passage from the Assayer where he stated that the book of nature was written in the "language of mathematics". " Does it mean that biomimicry is bound to theological commitments?

Although some fringe websites hint at connecting creationism with biomimicry principles, Benyus's own metaphysical views are closer to a holistic materialism. Humans are an integral part of the system of life; they are just "one vote in a parliament of 30 million (perhaps even 100 million), a species among species” (Benyus, 1997: 8). They consequently should act from within nature and try to fit in with nature's patterns (Dicks 2016). While this ethos is close to the program of integration of human production in nature's cycles advocated by the early champions of the bioeconomy and by ecodesigners, it has generated a specific metaphysical view of life, advocated by Freya Mathews (2011). This rests on two major assumptions: the conativity of living beings and the synergy between them. Living beings have an impulse to preserve and increase their own existence. They exist to serve their own ends, and in order to achieve their ends, they have to accommodate the desires of others, to mutualize their ends. In this metaphysical framework, nature is a process (natura naturans), rather than an overall order (natura naturata). Moreover ethical prescriptions are derived from biology. As Mathews puts it, "we need to allow the wider life dictate our desires, as well as provide

\footnotetext{
4 "Philosophy is written in this grand book - I mean the universe — which stands continually open to our gaze, but it cannot be understood unless one first learns to comprehend the language and interpret the characters in which it is written. It is written in the language of mathematics, and its characters are triangles, circles, and other geometrical figures, without which it is humanly impossible to understand a single word of it; without these, one is wandering around in a dark labyrinth". Galileo The Assayer, Rome, 1623, transl by S. Drake in Discoveries and Opinions of Galileo , 1957, p. 237-8.
} 
blueprints for the means we use to achieve our desires", such that we definitively break with the vision of nature "as a storehouse of readymade designs available for us to mix and match to our consumer purposes" (Mathews 2011: 373-374). Biomimicry thus generates an ecocentric perspective, in which biomimesis is undertaken for the interest of the Earth as ecosystem, of which humans are but a part.

The weak metaphysical framework is instantiated in Peter Sloterdijk's notion of "homeotechnology". In the course of his interviews with Hans-Jürgen Heinrichs, translated into English as Neither Sun nor Death, he coins this term to refer to the imitation of nature by technology: "It seems that we find ourselves, for the first time, on the threshold of a form of technology which will be sufficiently developed to pass itself off as a radical imitation of nature" (Sloterdijk \& Heinrichs 2011: 329). Sloterdijk describes this change as a shift in the early twenty-first century from "allotechnology" to "homeotechnology". The former refers to modern technology where humans are outside nature, strangers, aliens (from Greek allos meaning other); the latter to a new style of technology in which humans are embedded in nature. The distinction could also refer to the contrast mentioned above, between exploiting nature's resources and exploring nature's resources. It is because we are learning from nature that technology gradually becomes more and more like nature (from Greek omoios meaning similar). Sloterdijk ascribes the so-called homeotechnological turn to the conjunction of climate change and access to the nanoscale. The climate crisis forces us to consider the Earth as our "innerspace" and take into account the ecological impact of our technology, while the access to the nanoscale blurs the boundary between the natural and the artificial, between natural molecular machines and manmade machines. So imitation works both ways: biomimicry can be technology mimicking biological processes or technology mimicking the natural process of genetic modification in biotechnology. This is definitely something different than the version of biomimicry that Benyus called for. 
Sloterdijk's description of the emerging form of homeotechnology emphasizes primarily the integration of artefacts within natural processes and their cooperation with natural phenomena, which marks the end of the ideal of mastery over nature underlying allotechnology. "Nature can only be imitated after the rupture with the technology of wastage, which is always also something of a technology of violation" (Sloterdijk \& Heinrichs 2011: 330). For Sloterdijk, mimicking is precisely not a design strategy. The imitatio naturae appears as the end-result of a process of rapprochement with nature due to the access at the nanoscale and the climate crisis. Technology will look like nature. It will "pass itself off as a radical imitation of nature", and humans are still the major actors of this rapprochement. While Sloterdijk's homeotechnology does not fully share the ecocentric perspective of Benyus and Matthews (Blok 2017), both the weak and the strong metaphysical programs assume that imitation gradually will blur the boundaries between subject and object, between nature and culture, between living and non-living. But let us see if such a subversion of the main pillars of western metaphysics is at the core of all bio-informed practices. Is the rapprochement between phusis and technê a necessary and sufficient condition for bioinformed strategies?

\section{Biology as technology: The case of synthetic biology}

Synthetic biology seems to be a good candidate to address this issue for two major reasons. It is one of the major assets of the bio-economy, which is expected to replace the previous economy based on the oil and chemical industries. It is meant to contribute to a better integration of technology within nature since biofuels, biopolymers, and bacterial drug factories are less polluting and less energy intensive than chemical technology. As they yield recyclable products they are more respectful of the cycles of nature. On the other hand, 
synthetic biologists explicitly claim to blur the boundaries between nature and technology by designing living beings as artefacts. Biology is Technology is the title of a volume advertising synthetic biology (Carlson 2010). This bold assertion captures the program of synthetic biology: redesigning life. At first glance, synthetic biology instantiates the "second Renaissance" initiated by learning from the book of nature because it all started from "reading" the book of life. Synthetic biologists take advantage of high-throughput sequencing machines for "reading" genome sequences and they use automata designed for the synthesis of gene sequences to "rewrite" them. The ubiquitous code metaphor proved extremely inspiring. For instance, Craig Venter used it to claim that living organisms can now be designed on a computer (Venter 2007). With the new techniques of genome editing such as CRISPR-Cas9, it is possible to create a break in a genome on a specific chosen sequence and the cell's natural repair mechanism will then insert the synthetic sequence in the break. Whereas previous methods of mutagenesis were random, this technique enables targeted mutations in genomes and therewith a better control in the construction of artificial genomes out of natural ones.

Among the various research programs gathered under the umbrella of synthetic biology (Deplazes 2009), the protocell approach is focused on the chemical synthesis of lifelike cells. Like Stéphane Leduc, the French medical doctor who coined the phrase "synthetic biology" (Leduc 1912), contemporary synthetic biologists aim to define the physical-chemical conditions which can produce living structures. However, unlike Leduc they do not try to imitate the forms, colours, textures and movements of living organisms with osmotic growths. Rather, they build vesicles with lipid bi-layers in order to understand the basic conditions for the emergence of life out of the non-living. Their synthetic cells are mimicking in a laboratory the conjectural natural processes, which resulted in the emergence of living cells. They rely on a working definition of life based on three major characteristics - self-production, self- 
maintenance and evolution - which could be in agreement with Mathews's conativity principle without the synergy principle.

However, the most prominent research programs conducted in synthetic biology could not converge with the philosophy of biomimicry. Most synthetic biologists certainly blur the boundaries between nature and technology, but as they turn living organisms into artefacts, the "imitation" proceeds in the opposite direction. For instance, in the design of synthetic minimal genomes the living cell provides a chassis, a structural unit that can be functionalized by additional genes performing specific desirable tasks. As suggested by the chassis metaphor, the mechanics industry provides the model for the synthesis of living machines. The Biobricks program - which inspired the iGem competition ${ }^{5}-$ is oriented toward engineering "synthetic biological systems that behave as expected" (Endy 2005). It is a strict application of the standards and norms of conventional engineering - standardization, decoupling and abstraction - to living modules and systems. The aim is to build machine-like living organisms rather than life-like machines. ${ }^{6}$ The strategy consists in hijhacking a number of molecular modules found in living cells in order to get them performing specific unnatural tasks by reprogramming them and inserting them in a micro-organism. In this respect synthetic biology can be seen as the mirror image of bionics and of biomimetics as well. It is more a technomimetic construction of living organisms than a biomimetic construction of machines (Bensaude-Vincent \& Benoit-Browaeys 2011). It comes as no surprise that synthetic biologists have a poor opinion of biomimetic strategies and disqualify them as an unrealistic form of design doomed to fail. For instance, an editorialist of Nature Biotechnology described synthetic biology as an opportunity "to move away from mimicry", adding:

\footnotetext{
${ }^{5}$ iGem stands for International Genetically Engineered Machines.

${ }^{6}$ Indeed this strategy can be seen as a confirmation that our view of nature has always been impregnated with technology as Maurice Merleau-Ponty (1995: 120) clearly stated. From Aristotle to cybernetics, nature has been continuously reconfigured by dominant technologies（see Bensaude Vincent 2007, 215,2016)
} 
At the turn of the last century, the Wright brothers achieved manned flight not by mimicking natural systems, but by applying the principles of engineering and aerodynamics ${ }^{7}$. Similarly, synthetic biology allows us to dispense with biological mimicry and design life forms uniquely tailored to our needs (Anonymous 2009).

It seems that "reading the book" is not the key required for the "biomimicry revolution" to happen. Synthetic biologists have read the book of life but they are mainly concerned with rewriting it. The living machines that synthetic biologists engineer or re-engineer for technological purposes could pass as imitations of nature, they could fit in Sloterdijk's homeotechnology. However the bio-machines, which are the products of a rational design, are not the outcomes of a blind and contingent process of evolution and random selection. These "radical imitations" are a-historical beings which are not equipped to survive in natural environments, where they would be in competition with natural forms of life.

In editing new genomes synthetic biologists are certainly learning something. Making is a sure way of increasing our understanding, as they claim when they quote Richard Feynman's famous motto "what I cannot create I do not understand". However, learning a lot about nature is not learning from nature. Synthetic biologists are not students at the "school of nature". In their effort to design new forms of life, or to create life as it could be, they demonstrate instead their capabilities of challenging nature.

Moreover, synthetic biology is often presented as a second-generation bioengineering strategy quite distinct from the messy tinkering of early genetic engineering. Synthetic biologists are more concerned with gaining a better control over the bio-machinery, to make it as predictable as manmade machines, rather than taking inspiration from them. They are

\footnotetext{
${ }^{7}$ Remarkably the Wright brothers are used in support of opposite stances. In particular, Lewis (1934: 251) and Janine Benyus (1997: 8) ascribe their success in aerospace to their observation of birds' drag and flight.
} 
applying the knowledge gained from their synthetic practices to adapt nature to their technological purpose. In this respect they are quite far from the ecocentric perspective of the strong metaphysical program of biomimicry as they are keeping with the modern ideal of increasing our domination over nature rather than seeking a better integration of technology in nature.

Finally, the vanguards of synthetic biology stick to the view of Nature characteristic of modernity as a storehouse of resources available for technological projects. Through the billions years of contingent biological evolution, life has crafted robust devices and machines. These afford a toolbox for engineers to play with. The Lego metaphor pervades the Biobricks approach, which openly favours a gamification of synthetic biology through the amateur practices of garage biology (Bensaude-Vincent 2016). To be sure, synthetic biology is much more than a playful activity. It is strongly supported by public policies and venture capital because it is supposed to fuel the new era of the bioeconomy. The central concept of the bioeconomy outlined in the OECD policy agenda (OECD 2009) is that biorefineries will advantageously replace chemical refineries to produce biofuels and bio-based products. But relying on renewable resources does not alter the conventional view of nature as a mine of resources. On the contrary, it nurtures the conviction that resources are indefinite. It encourages the same utilitarian attitude that prevailed in the industrial revolution based on fossil fuels.

\section{Imitation through demarcation: The case of materials chemistry}

While blurring the boundaries between biology and technology is not a sufficient condition for bringing about the "Biomimicry revolution" expected by Benyus, is it at least a necessary condition? The bio-informed strategies developed by chemists and materials scientists tend to 
demonstrate that it is important to bear in mind that engineering is quite different from natural processes.

Biomimetic chemists are indeed learning a lot from nature. They have been picking up some exquisite structures, like lotus leaves for making hydrophobic materials, or shark's skin for making aero-dynamical materials, or the multifunctional structure of the woodpeckers' beeks to manufacture ice axes for climbing. However their practice of biomimetic design involves more than the imitation of parts and devices. As Julian F. Vincent convincingly argues in his study of the cuticle of which the exoskeleton of arthropods and insects is composed, the basic challenge in biomaterials is how to integrate conflicting properties in the same material: stiffness for stability and protection must be traded against mobility and transmission of information about the environment as well as with recyclability. The lesson derived from these in-depth studies of biological design is that "technology should be aiming at producing not just very small components but integrated assemblages of components" (Vincent 2005: 77). Although some biomimetic devices may prove to be successful, true bioinspiration should proceed from a more holistic view of machines operating in their technological environment.

For instance, nature-informed chemical engineering (acronym NICE) aims at optimizing reactors and catalysts by looking at the chemical and geometrical features of nature both at the level of the building blocks and at the supramolecular level. It aims at designing hierarchical materials combining porous building blocks for efficiency and tree-like structures, i.e. fractal structures, for transport (Coppens 2012). Fractal structures, investigated most famously by Belgian mathematician, Benoit Mandelbrot, are characterized by the repetition of the same pattern at various scales, such that the nanoscale pattern looks the same as the macroscopic one. In a tree or lung, for instance, the network of branches is the same at 
all scales. This self-symmetrical geometry enables fast and uniform transport of fluids from the stem to the leaves or the large surface cells.

Biomimetic strategies in materials research are not just the key to improve conventional chemical processing; they also have a deeper impact on the chemists' professional practices. Conventional chemical processes of fabrication consist in first cracking the complex molecules of hydrocarbons made up by living beings along hundreds of thousands of years and then reassembling the components into functionalized molecules. Both processes require high pressure and high temperatures and generate by-products. As chemists cooperate with marine biologists and better understand the growth of minerals they have learnt how to make complex structures from the nanoscale to the macroscopic level in mild chemical conditions (without high pressure and high temperatures), with lower consumption of energy and less release of polluting by-products. The lessons concerning structures and processes allow chemists to create a new class of materials with unprecedented properties such as nanospheres, platelets, nanotubes, or nanocylinders. Their strategy is to gather inorganic precursors (silica for instance) that self-assemble in an organic template (a peptide in many cases). The goal is to obtain a synergistic effect between the template and the silica components so that they grow in quasi-concerted manner. In this case nature provides the model of a dynamic process of interaction that yields a hierarchical structure.

A major lesson that chemists have learnt from nature is self-assembly, a collective behaviour of molecules, which spontaneously arrange themselves in ordered patterns. They self-assemble in the templates through a process tightly controlled at each level. Selfassembly is ubiquitous in living systems, especially in biominerals. It is the ultimate dream for the design of materials at the nanoscale, where human hands and conventional tools are helpless. In addition, it is extremely advantageous from a technological point of view, because it is a spontaneous and reversible process with little or no waste and a wide domain of 
applications. In this respect, biomimetic strategies could converge with the bio-inclusive approach outlined in the philosophy of biomimicry. In particular their focus on "soft machines" meets the concerns of biomimicry for sustainability, since they are more flexible, more efficient and consume less energy. Biomimetic chemists also recommend adapting and combining simple materials instead of looking for new materials with new functionalities, a guiding principle very much in favour of eco-sufficiency. More generally, they share a preference for a systems approach aimed at designing integrated assemblages instead of very small components as they try to turn the physical constraints of the milieu into resources. Such guiding principles proceed from philosophical convictions not dissimilar to the metaphysical agenda of biomimicry.

However while biomimetic chemists might be interested in reconciling technology and nature they are more concerned with stressing the distance between them. They are aware that it is a real challenge to translate what they have learnt about the complex architecture of biomaterials into technological materials.

This translation of natural design blueprints requires a fundamental mechanistic understanding of materials and interfaces ranging from the macro-to the nanoscale - a range that could extend over six or ten orders of magnitude.[...] Rather than resolving every single atom, the key is to uncover the essential structural, physical or chemical features in the natural model that underlie those extraordinary properties. [...] We posit that to take optimal advantage of bio-inspiration in improving the design of functional materials, the relation between the structure and the function of a biological material has to be investigated, taking into account differences in context and constraints between the biological model and a technical application. (Trogodas et al. 2016: 4017)

Significantly, Vincent, who pioneered the biomimetic design of materials in the 1980s, insists that biomimetics as a strategy of technological design involves a clear recognition of 
the distance between biology and technology (Vincent et al. 2006). He convincingly argues that biomimetics requires a procedure of interpretation, extracting the general principles behind the genesis and functioning of the biological model, followed by a procedure of translation into technological actions. Translation is not a transfer of technology and it undermines the naïve view that nature has found the solutions to our problems. Such a claim involves two fallacies. First, biological ways of solving problems differ profoundly from technological ones. Over billions of years, biological evolution and natural selection have produced sophisticated molecular machines all over the planet Earth. Human engineers cannot work on such a timescale and use so much space. The technosphere faces time and space constraints, as well as economic and regulatory pressures that biological evolution ignores. By contrast, in the technosphere engineers can manipulate temperature and pressure, which are much less malleable in biological evolution.

Second, a solution is relevant only in relation to a problem. As Vincent points out, strictly speaking nature does not afford any solution since we don't know what her problem was. Therefore the process of "translation" requires a deep understanding of biology, not only of structural biology and genomics, but of evolutionary and development biology as well. By applying a design tool for inventive problem solving, known as TRIZ, Vincent claims that there is only an average of $10 \%$ overlap between biological and engineering in terms of design solutions (Vincent 2005). In sum, biomimetic chemists emphasize that imitation requires a clear distinction between the source and the result. Artists know for sure that the image on their canvas differs from the model. ${ }^{8}$ Mimesis is by no means a process of replication or reproduction. The product of a biomimetic strategy of design will never be a replica of the original. For instance the semi-synthetic molecule of Taxol, used as an anticancer drug, cannot be considered as a replica of the substance grown in the bark of yew trees,

\footnotetext{
${ }^{8}$ For instance René Magritte's famous painting entitled "Ceci n'est pas une pipe" was a reminder of Plato's argument against the prisoners in the cave who mistake the copy for the original.
} 
despite its similar structure and properties. It may be better than a simple ersatz as a substitute, but it results from a process of abstraction and translation. Its mode of existence deprived of the conativity and the synergy mechanisms characteristic of living organisms is quite different.

There is a striking contrast between the chemical approach to biomimetics, which rests on a clear demarcation between nature and technology, and the ecological inspiration of biomimicry, which urges for the inclusion of technology within nature. The reason seems to be that unlike the advocates of biomimicry, biomimetic chemists do not trust biology. They are keen to take inspiration from life, they highly value self-assembly, but they tend to consider biomimicry as a romantic and unrealistic view of engineering, precisely because they share with the advocates of bionics and of biomimicry the vision of nature as a complex and dynamic system. Given their complexity, biological phenomena present emergent properties and unpredictable behaviour that are not compatible with engineering. ${ }^{9}$

\section{The challenges of reconciliation: The case of soft robotics}

The traditional engineering ethos prescribes to reduce risk to a minimum (MacLeod 2012). Modelling the object, planning the process, and controlling the implementation, i.e. anticipating the future, is the basic rule. Such guidelines are not compatible with the strong metaphysical program of biomimicry, as they belong rather to the modern ideal of mastery over nature. In addition, engineers have to follow specifications and standards of production. They have obligations and responsibilities. Finally, they have to comply with the ethical rules and social norms of their countries. So it is clear that the current ethos of engineers is at odds with the ideal of biomimicry and would require a deep revision. Accepting failure maybe the price to pay for mimicking living creatures.

\footnotetext{
${ }^{9}$ Even chemists as famous for their invention of life-like machines as Stoddart (2016 Nobel Prize for his work on molecular machines) do not encourage biological machines and instead favour hybrid bio-chemical devices. Chemists, he claims, should embrace the specificities of their own discipline and emancipate themselves from biological models when designing programmable devices for use in challenging environments (Boyle et al. 2011).
} 
Given such constraints, is it reasonable to engineer biomimetic machines that develop the unpredictable emergent properties and behaviour of actual bio-machines, i.e., living beings? This is the challenge of bio-informed cognitive technology, such as soft robotics. It is a branch of robotics aimed at understanding embodied intelligence and using unconventional materials, with properties such as elasticity, viscosity, softness, density and stickiness. A research community of soft robotics has emerged which opens up the perspective of alternative robotics based on the investigation of "smart" behaviours in insects or plants. The models are living creatures, which bear no obvious resemblance to humans but have nevertheless developed behavioural capacities that seemed to require a human brain according to the philosophical humanist tradition or at least an animal brain according to the more recent science of ethology. Soft robotics thus invites to extend cognitive ethology to the plants realm. $^{10}$

For instance, a contemporary research project in micro-robotics to design robots capable of sensing pollution in soil, food, air, or water takes its inspiration from the capabilities of plant roots (Mazzolai et al. 2014). Plant roots are capable of detecting odours without a nose, of sensing light without eyes, of breathing without lungs, moving without muscles, communicating without mouths and making decisions without a brain. Understanding how plant roots manage to perform such remarkable tasks at low energy cost allows one to come up with unconventional design principles. First, let the robot build its own body for growing from the tip by adding new cells; this model allows faster penetration and needs lower power.

\footnotetext{
${ }^{10}$ Cognitive ethology could even be extended to cell biology if we take into account the current research program on cell mobility. It relies on the assumption that a central system of control is not required for smart and complex behaviours (Arroyo, DeSimone 2014). Living cells move through coordinated shape changes by using the constraints arising from the milieu. They take advantage of their elastic properties to move passively according to the constraints of the environment. In this case, the intelligence is not only embodied in the material itself, it is distributed between the environment and the "machine".
} 
Second, having bending capacities associated with the growing capacities is key for avoiding obstacles. Third, sensing and actuating should be coupled in the same material.

Soft robotics thus features as a good candidate for reconciling various trends of bioinformed design. First, as it bridges the gap between humans and other living beings, it fits in with one major aspect of the philosophical framework of biomimicry. It challenges the proud position of humans as outsiders, occupying a special place in the universe and dominating nature. Soft robotics rests on the conviction that intelligence is not what is displayed in goaloriented tasks. It rather associates intelligence to modes of survival in a hostile environment, described as the achievements of "embodied minds" (Iida and Laschi 2011). Accordingly, researchers in soft robotics give up the idea of central control in favour of a continuous process of adjusting the robot to the perturbations of the environment through peripheral sensors and actuators. This strategy relies on the view of living beings and machines as dynamic and relational entities, which is the hallmark of the strong metaphysical agenda of biomimicry.

Second, soft robotics scientists converge with biomimetic chemists because they need the knowledge and skills of the latter. In order to translate their fascinating investigations of living machines into technological terms they will have to use the same guiding principles for designing soft machines (Jones 2004). Soft robots not only require soft materials but also have to use the environment and incorporate energy in the design phase. Biomimetic chemists and soft robot scientists will have to cooperate and learn how to do this using stochasticity as much as determinism, and relying on evolutionary adaptive behaviours to the environment. The design of soft robots remarkably exemplifies the process of individuation or concretization of technical objects described by the French philosopher, Gilbert Simondon (1958). Not only is the milieu incorporated into the functioning of the machine, but biomimetic robots are never completed, endlessly growing and learning through their 
continuous responses to changes in the environment. Soft robotics thus calls for a vision of technology fully integrated into the environment, but at the same time it raises the question of human control over such machines. Simondon critically commented on the cult of automation: he despised automata, i.e. autonomous machines, as closed and abstract technical objects. He instead praised open machines, which require humans as organizers. Similarly bio-informed strategies in soft robotics could lead to give up the ideal of automation in favour of a subtle orchestration of the continuous interactions between machines and their associated milieu by humans.

But what about growing soft robots? What kind of monitoring and stewardship can we have since their behaviour requires many degrees of freedom? Autonomous robots have a long history in science fiction but what will be their actual mode of existence if they acquire emergent properties and generate artificial evolution?

With a view to answering this question, let us briefly recapitulate the specific features of this kind of bio-informed practice. While soft robotics employs soft and plastic materials like biomimetic chemistry, it considers living entities as computational machines like synthetic biology. Clearly, soft robotics has roots in the early movement of bionics developed by cyberneticians. As Jean-Pierre Dupuy argued, cognitive technology is the continuation of cybernetics: it relies on the same metaphysical program of the naturalization or mechanization of the mind (Dupuy, 2000). Indeed, the model of the mind involved in early bionics has changed. While cybernetics was focused on thinking as a computational activity, soft robotics is concerned with the algorithms underlying a variety of intelligent behaviours, and which do not require a brain. Intelligent and complex behaviours may emerge from material and peripheral properties rather than from a central brain controlling the system. Yet the metaphysical framework underlying the bio-informed practices developed in soft robotics 
differs profoundly from the eco-centric, eco-friendly philosophy of biomimicry outlined in the beginning of this paper.

By contrast, the metaphysical framework of bionics resurfaces in the chemists' practices of biomimetics at the nanoscale. Inducing the self-assembly of molecules to obtain ordered structural patterns or "growing a robot" is not like fabricating a machine by assembling individual parts. Supramolecular chemists and soft roboticians induce spontaneous highly selective interactions and then let them go to work. They initiate and monitor the system but they do not literally design it. Like sailors at sea who must adapt their behaviour to the wind and the waves, they are just initiating and steering spontaneous processes. Indeed chemical engineers such as Coppens claim that biomimetic engineering achieves control over chemical and geometrical phenomena, even if nonlinear phenomena are involved in the propagation of liquids between cells in a tree-like fractal network. Still, nonlinear effects and emergent properties are key for the design of elegant structures and optimized processes, but they are not fully controllable. The paradox is that designing at the molecular scale is meant to improve control and precision, to substitute more or less empirical tinkering for rational design, while at the same time one major aim is to obtain nonlinear effects and emergent properties. The will for emergence and "out-of-controlness" is, according to Dupuy, the core project of cognitive science in the NBIC (Nano-Bio-Information and Cognitive science) program of converging technologies. He accordingly updates the sorcerer's apprentice myth: "It is neither by error nor by terror that mankind will be dispossessed from its own creations but by design, which henceforth is understood to signify not mastery but non-mastery and out-of-controlness" (Dupuy 2009: 57).

In this perspective, taking inspiration from nature certainly means giving up the modern paradigm of humans as masters of the world but not for the benefit of Benyus's modest view of humans as "one species among million species". It leads rather to the view of 
sorcerer's apprentices who generate machines and materials that virtually make themselves, and may do so for any purpose.

\section{Concluding remarks}

While synthetic biology, materials chemistry and soft robotics are fast becoming leading disciplines in the field of molecular-scale bio-inspired design practices, it is interesting to note that none of them squarely fits in the three major trends designed for macro-scale practices (Table 2). Instead, lose connections can be found between the three emerging disciplines and all three existing trends. Synthetic biology has more affinities with bionics than with biomimetics and biomimicry. Whilst materials chemistry seems to fit in the biomimetics trend, it introduces a new distance between nature and technology. Soft robotics, which is clearly the heir of bionics introduces the idea decentralised intelligence, as opposed a central control.

Table 2: How do emerging bio-informed design practices fit within existing major trends?

\begin{tabular}{|l|l|l|l|}
\hline Major trends & Synthetic biology & Materials chemistry & Soft robotics \\
\hline Bionics & $\begin{array}{l}\text { Reductionist } v s \text { systems } \\
\text { approach } \\
\text { Shared vision of living } \\
\text { organisms as } \\
\text { computational machines }\end{array}$ & $\begin{array}{l}\text { Shared engineering ethos } \\
\text { and culture }\end{array}$ & $\begin{array}{l}\text { Shared systems approach } \\
\text { \& computational vision } \\
\text { of life } \\
\text { Embodied intelligence } v s \\
\text { brain control } \\
\text { Challenge of losing } \\
\text { control }\end{array}$ \\
\hline Biomimetics & $\begin{array}{l}\text { Hijhacking } v s \text { translating } \\
\text { biological structures and } \\
\text { processes } \\
\text { Redesigning life } v s \\
\text { learning from life }\end{array}$ & $\begin{array}{l}\text { Shared problem-solving } \\
\text { activity aimed at } \\
\text { designing optimal and } \\
\text { reliable technological } \\
\text { solutions }\end{array}$ & $\begin{array}{l}\text { Shared activities } \\
\text { abstraction, translation }\end{array}$ \\
& $\begin{array}{l}\text { Shared goal of promoting } \\
\text { sustainable technology in } \\
\text { neoliberal bioeconomy. }\end{array}$ & $\begin{array}{l}\text { More focus on reliability } \\
\text { than sustainability } \\
\text { between biology and } \\
\text { technology } v \text { imitation } \\
\text { as replication }\end{array}$ & $\begin{array}{l}\text { Shared vision of the } \\
\text { complexity of nature } \\
\text { Focus on innovation } \\
\text { rather than sustainability }\end{array}$ \\
\hline Biomimicry
\end{tabular}


Far from being perceived as a weakness, the variety and disunity of bio-informed technologies is to be seen as an indicator of the vitality of the movement. As the pluralism of philosophical views and commitments creates tensions and discussions, it offers a robust safeguard against the process of oversimplification and dogmatization that prompts the rapid decay of fashionable trends. In fact, the superficial agreement around the wonders and virtues of bio-inspiration might quickly collapse, when it comes to the definition of the research priorities and specific technological choices in the context of the bioeconomy.

The divergences between the philosophical commitments underlying the three bioinformed practices outlined in this paper deeply impact the program of bioeconomy, So what could be the contribution of bio-informed technologies to the bioeconomy? They obviously contribute to spreading the specific view of nature as inherently renewable and efficient (not energy intensive). However, the various points of friction identified in this paper between biomimicry, biomimetics and bionics may generate two contending politics of the bioeconomy: on the one hand, the old notion of bio-economy developed by René Passet (1979, 2012) among others, is in full agreement with the metaphysical agenda of biomimicry; on the other hand, the more recent notion of a knowledge-based-bio-economy, promoted by OECD and the European Commission (mentioned in the introductory section) is strongly supported by one of the advocates of biomimicry, Aberkane. The former aims at environmental sustainability, the latter aims at reconciling economic and environmental sustainability (Birch et al. 2010, Levidov et al. 2012). The bioeconomic model shaped on the strong version of biomimicry is an alternative to neoliberal capitalism. Instead of emphasizing competitiveness, productivity, efficiency, standardisation and globalisation, it favours local solutions aimed at securing environmental health, at reducing the causes and mitigating the effects of climate change. The bioeconomic model shaped on the philosophy of biomimetics and bionics would instead favour a neoliberal use of bio-informed technology. In mimicking nature's capacities 
to create new resources at the molecular level and to generate machines that can self-regulate and self-reproduce, it enables the continuous expansion and accumulation of capital. In this bioeconomic model, bio-informed technologies provide the basis for creating sustainable capital and not just to sustain capitalism. It leads to a "real subsumption of nature" (Boyd et al 2011: 562), which is quite the opposite of the reconciliation with nature advocated by Benyus.

It is therefore important clearly to identify the points of convergence and divergence between the various trends of bio-informed approaches to design in order to open a democratic debate among the various actors of the movement.

Acknowledgements: I am grateful to the anonymous referees, Henry Dicks, Vincent Block, and Emmanuelle Bensaude, who helped improve the earlier versions of this paper.

\section{References}

Aberkane, I. 2015. Audition au Conseil économique et social.

http://www.dailymotion.com/video/x2joni8. Retrieved January 2017

Anonymous. 2009. 'Unbottling genes'. Nature Biotechnology, 27 (12): 1059.

Arroyo, M., DeSimone, A. 2014. 'Shape control of active surfaces inspired by the movement of euglenids'. Journal of the Mechanics and Physics of Solids. 62: 99-112.

Bensaude-Vincent, B., 2007. 'Reconfiguring nature through syntheses: From plastics to biomimetics', in Bensaude-Vincent, B., Newman, W., (eds), The Natural and the Artificial. An Ever-Evolving Polarity, Cambridge MA, MIT Press, p. 293-312.

Bensaude-Vincent, B. 2016. 'The moral economy of synthetic biology' in J. Boldt ed. Synthetic Biology. Metaphors, Worldviews, Ethics and Law, p. 87-100. Wiesbaden: Springer Bensaude-Vincent, B., Benoit-Browaeys D. 2011. Fabriquer la vie. Où va la biologie de synthèse. Paris: Seuil. 
Benyus, J. 1997. Biomimicry, Innovation inspired by Nature. New York: Quill William Morrow. Reprint New York: Harper Perennial, 2002.

Birch, K, Levidow, L. Papaioannou T. 2010. 'Sustainable capital? The neoliberalization of nature and knowledge in the European knowledge-based bio-economy'. Sustainability. 2: 2898-2918.

Blok, V., Gremmen, B. 2016. Ecological innovation: Biomimicry as a new way of thinking and acting ecologically'. Journal of Agricultural and Envionmental Ethics. 29 (2): 203-217. Blok, V. 2017. 'Earthing technology: Towards an ecocentric concept of biomimetic technologies in the anthropocene', Techné: Research in Philosophy and Technology, DOI: $10.5840 /$ techne201752363

Boyd, W., Prudham, S., Schurman, R. 2001. 'Industrial dynamics and the problem of nature. Society \& Natural Resources. 14 : 555-570.

Boyle, M., Smaldone, R., Whalley, A.C., Ambrogio, M.W., Stoddart, J.F. 2011. 'Mechanised Materials. Chemical Science. 2: 204-210.

Carlson, R.H. 2010. Biology is Technology: The Promise, Peril, and New Business of Engineering Life. Cambridge MA: Harvard University Press.

Coppens, M.O. 2012. 'A nature-inspired approach to reactor and catalysis engineering'. Current Opinion in Chemical Engineering. 1: 281-289.

Deplazes, A. 2009. 'Piecing together a puzzle'. EMBO Reports. 10: 428-432.

Desplazes, A., Huppenbauer, H. 2009. 'Synthetic organisms and living machines. Positioning the products of synthetic biology at the borderline between living and non-living matter'. Systems and Synthetic Biology. 3: 55-63.

Dicks, H. 2016. 'The philosophy of biomimicry'. Philosophy of Technology. 29: 223. doi:10.1007/s13347-015-0210-2. 
Dicks, H. 2017. 'Environmental ethics and biomimetic ethics: Nature as object of ethics and nature as source of ethics', Journal of Agricultural and Environmental Ethics, 30: 255-274.

Dupuy, J.P. 2000. The Mechanization of the Mind. Princeton: Princeton University Press. Revised paperback ed. MIT Press, 2008.

Dupuy, J.P. 2009. 'Cybernetics is an antihumanism: Advanced technologies and the rebellion against the human condition'. AntiMatters. 3 (2): 47-64.

Elden, S, Mendieta, E. 2009. 'Being-with as making worlds. The second coming of Peter Sloterdijk'. Environment and Planning D: Society and Space. 27:1-11.

Endy, D. 2005. 'Foundations for engineering biology'. Nature. 438 : 449-453.

Geselowitz, D.B. 1998. 'In Memoriam: Otto H. Schmitt'. Annals of Biomedical Engineering, 26(5): 739-740. doi: http://dx.doi.org/10.1114/1.127

Iida, F, Laschi, C. 2011. 'Soft robotics: Challenges and perspectives'. Procedia Computer Science. 7: 99-102.

Iouguina A., Dawson J.W., Hallgrimsson B., Smart G. 2014. 'Biologically informed disciplines: A comparative analysis of terminology within the fields of bionics, biomimetics, biomimicry and bio-inspiration, among others'. Journal of Design \& Nature and Ecodynamics. 9 (3):197-205.

ISO (International Organization for Standardization )18458, 2015. Biomimetics -Terminology, concepts and methodology. https://www.iso.org/standard/62500.html. Retrieved October 2017.

Jones, R. L. 2004. Soft Machines. Nanotechnology and Life. New-York: Oxford University Press

Leduc, S. 1912. La Biologie synthétique. Paris : A. Poinat Maynard. Levidov, L. , Birch, K Papaioannou, T. 2012. 'EU agri-innovation policy: Two contending visions of the bio-economy'. Critical Policy Studies. 6 : 40-65. 
MacLeod, I. 2012. 'Ethos of Professional Engineering'. http://www.profeng.org/epec/Ethosen-IM.pdf.

Mathews, F. 2011. 'Towards a deeper philosophy of biomimicry'. Organization \& Environment, 24 (4): 364-387.

Mazzolai, B, Beccai, L., Mattoli, V. 2014. 'Plants as models in biomimetics and biorobotics: New perspectives. Frontier in Bioengineering \& Biotechnology.2: 1-5.

Merleau-Ponty, M., « La Nature » in Notes. Cours du Collège de France (1956-1957), Paris, Éditions du Seuil, 1995, p. 120.

OECD 2009. The Bioeconomy to 2030: Designing a Policy Agenda http://www.oecd.org/sti/futures/long-termtechnologicalsocietalchallenges/42837897.pdf Passet, R. 1979. L'économique et le vivant. $2^{\text {nd }}$ ed. Paris: Economica, 1996. Passet, R. 2012. La bioéconomie de la dernière chance. Paris: les liens qui libèrent. Sloterdijk, P, Heinrichs, H.J. 2006. Die Sonne und der Tod. Engl. transl. by S. Corcoran. 2011. Neither Sun nor Death. Los Angeles, Semiotexte.

Simondon, G. 1958. Du mode d'existence des objets techniques. Paris: Aubier. $2^{\text {nd }}$ edition 1989.

Van der Hout, S. 2014. 'The Homeotechnological Turn: Sloterdijk’s response to ecological crises'. Environmental Values. 23: 423-442.

Van Lunteren F. 2016. 'Clocks to computers. Some clarifications', Isis, 107/4: 800-804. Venter, C. 2007. 'A DNA-Driven World: The $32^{\text {nd }}$ Richard Dimbleby Lecture'. BBC One, December 4, 2007. www.bbc.co.uk/pressoffice/pressreleases/stories/2007/12_december/05/dimbleby.shtml Retrieved January 2017

Vincent, J. F. 2005. 'Deconstructing the design of a biological material', Journal of Theoretical Biology, 236 (1): 73-78. 
Vincent, J.F., Bogatyreva O., Bogatyrev N., Bowyer A., Pahl A.K. 2006. 'Biomimetics : Its practice and Theory'. Journal of the Royal Society Interface, 3: 471-482.

http://rsif.royalsocietypublishing.org/content/3/9/471.full Retrived January 2017.

Vogel, S. 1998. Cats' Paws and Catapults. Mechanical Worlds of Nature and People. New York London: Norton \& Company.

Wahl, D.C., Bionics vs. biomimicry: From control of nature to sustainable participation in nature. Design and Nature III: Comparing Design in Nature With Science and Engineering, Vol. 87, ed. C.A. Brebbia, WIT Press: Ashurst, UK, 2006. doi: http://dx.doi.org/10.2495/ $\operatorname{dn} 060281$ 